\title{
A Política Externa Mexicana de Direitos Humanos durante o Governo Fox (2000-2006): As Estratégias de Lock-in e Sinalização* Bruno Boti Bernardi**
}

\section{Introdução}

Nos mais de setenta anos em que esteve no poder ocupando a Presidência (1929-2000), o Partido Revolucionário Institucional (PRI) não baniu constitucionalmente os partidos de oposição, nem empregou repressão sistemática contra seus opositores, tal como se viu nos regimes militares do Cone Sul. O regime era autoritário, mas eleições regulares eram realizadas, ainda que a natureza das instituições eleitorais fosse bastante enviesada em favor do PRI e o pluralismo político fosse bastante limitado.

O regime autoritário mexicano se havia originado da revolução social

\footnotetext{
* Artigo recebido em junho e aceito para publicação em agosto de 2010. Este artigo é baseado na Dissertação de Mestrado do autor, intitulada $\mathbf{O}$ processo de democratização e a política externa mexicana de direitos humanos: uma análise ao longo de duas décadas (1988-2006), a qual contou com o financiamento de bolsas da FAPESP e CNPq.

** Doutorando em Ciência Política pela Universidade de São Paulo (USP). E-mails: brunoboti@gmail.com; bboti@uol.com.br.
} 
de 1910, a primeira do século XX, que, uma vez terminada, por volta de 1917, assistiu ao processo de criação e institucionalização de um sistema presidencial altamente centralizado atrelado a um sistema de partido hegemônico ${ }^{1}$ que incorporaria os principais setores populares do país em uma estrutura corporativista vertical, autoritária e coercitiva. As características institucionais do regime autoritário mexicano em especial a existência de um partido político forte, controlado pela Presidência, capaz de organizar e competir nas eleições, e também de controlar importantes setores da sociedade por meio da sua estrutura corporativista - ajudam a explicar a sua longevidade política (CRESPO, 1999; ORTIZ, 2008, p. 51-52), de mais de sete décadas, que até hoje ainda não foi superada por nenhum outro regime autoritário do mundo.

A terceira onda democrática (HUNTINGTON, 1994) atingiu a América Latina na década de 1980, e o México fez parecer que a ela se juntaria cedo quando, em 1977, o regime autoritário mexicano implementou uma reforma eleitoral liberalizante significativa. Tal reforma possuía já um antecedente, a reforma eleitoral de 1962, que havia introduzido mecanismos de representação proporcional para a eleição dos membros da Câmara de Deputados (LUJAMBIO, 2000, p. 24). Todavia, apesar dessas duas reformas, a transição mexicana rumo à democracia seria prolongada e bastante gradual, além de levar mais de duas décadas, enquanto os outros países latino-americanos adentraram a década de 1990 já como regimes democráticos.

Durante o processo de democratização de sistemas de partido hegemônico, como o mexicano, a oposição tem de derrotar o partido associado com o passado autoritário nas urnas; e o partido hegemônico, por sua vez, precisa ainda abandonar o controle de que dispõe do processo eleitoral para que a transição de fato se consolide (MAGALONI, 2005, p. 121-123). No México, esses dois processos - de crescimento eleitoral da oposição e de abandono do controle autoritário sob as instituições eleitorais pelo PRI - estavam em gestação desde o início da década de 1980, mas foi só no final do decênio, sobretudo depois das eleições de 1988, que eles se aceleraram, até culminarem, no governo Zedillo, nas reformas eleitorais definitivas de $1996^{2}$ e na 


\section{A Política Externa Mexicana de Direitos Humanos du-}

perda da maioria de cadeiras do PRI na Câmara dos Deputados, em 1997.

As eleições de 1988 marcam o início do processo de transição democrática porque pela primeira vez as oposições contavam com suficiente poder negociador nas instituições, sobretudo na Câmara dos Deputados (onde o PRI havia perdido a maioria qualificada) para influenciar efetivamente o redesenho da normatividade política do país. Depois de uma mudança das preferências do eleitorado, resultante da crise econômica iniciada em 1982 que desgastou as bases de apoio do PRI, a oposição conseguiu que o equilíbrio institucional produzido pela eleição de 1988 potencializasse seu poder de negociação. A partir de então, os partidos políticos de oposição conseguiram pactuar com o regime diversas reformas que tornaram as eleições cada vez mais limpas e competitivas, até que em 2000 o PRI perdeu a Presidência da República, último indicativo de que o sistema autoritário de partido hegemônico se havia convertido, por fim, em uma democracia multipartidária.

Durante a transição, os dois últimos governos do PRI, dos presidentes Carlos Salinas de Gortari (1988-1994) e Ernesto Zedillo (1994-2000), em meio a um contexto de crises política e econômica que tornavam o regime mais vulnerável e sensível a custos de reputação e de imagem, realizaram uma série de mudanças na política externa mexicana de direitos humanos e em práticas e políticas domésticas nessa matéria em resposta às pressões e campanhas de shaming da rede transnacional de direitos humanos (COVARRUBIAS, 1999; 2008; TREVIÑO RANGEL, 2004; MAZA, 2008; ANAYA, 2009). O governo Fox (2000-2006), do Partido Ação Nacional (PAN), de centro-direita, primeiro governo não priísta desde 1929, coroaria essas mudanças prévias, mas desta vez com a implantação de uma política ativa de promoção dos direitos humanos estabelecida como objetivo central da política externa.

O objetivo deste artigo é analisar o impacto da democratização mexicana sobre a questão dos direitos humanos nas relações exteriores do México durante o governo Fox, buscando entender que 
papel a transição democrática mexicana desempenha na adoção de uma plataforma inédita de política externa que transformou os direitos humanos em um tema central do país na cena internacional. Nossa hipótese é a de que as mudanças na política externa mexicana de direitos humanos não foram resultado da pressão exercida pela rede transnacional de ativistas, como havia ocorrido nos dois governos anteriores. As mudanças foram iniciadas endogenamente pelo governo, que buscava ancorar (lock-in) (MORAVCSIK, 2000) a nova situação democrática do México no exterior por meio de compromissos internacionais de direitos humanos e democracia para, com isso, tentar reduzir a incerteza política e as possibilidades de retrocessos que marcavam o contexto político do recémdemocratizado regime mexicano. Buscava-se, ademais, assegurar e convencer as audiências internacionais sobre a credibilidade dessa nova postura do Estado mexicano com relação às reformas democráticas e os direitos humanos.

Nesse período, a nova elite governante que ascendia à Presidência depois da permanência do PRI por mais de sete décadas na instância máxima do Poder Executivo se deparou com um contexto político marcado por um grau significativo de incerteza quanto ao futuro da transição democrática. O regime priísta é ainda hoje o caso mais longevo de autoritarismo no mundo, e mesmo com a alternância no poder e o fim do processo de democratização o PRI continuou a ser uma das mais importantes forças políticas do país. A forma como se desenrolou a transição democrática no México, de maneira lenta, gradual e controlada muitas vezes pelo PRI, não implicou o desaparecimento nem o enfraquecimento definitivo do partido associado com o passado autoritário do país, de tal modo que o governo do PAN da emergente democracia mexicana buscou, com as profundas mudanças da política externa de direitos humanos, uma forma de ancorar no exterior a nova situação democrática, tentando blindá-la de possíveis regressos autoritários. Ademais, as mudanças cumpriam ainda outro objetivo: sinalizar de maneira crível para as audiências domésticas e internacionais a nova natureza (e imagem) do regime (MANSFIELD; PEVEHOUSE, 
A Política Externa Mexicana de Direitos Humanos durante o Governo Fox ...

2006; 2008; HAFNER-BURTON et al., 2008), bem como seu compromisso efetivo com o respeito aos direitos humanos e a consolidação democrática, em contraposição ao passado priísta autoritário.

\section{Democracias Emergentes e o Comprometimento Internacional com o Regime de Direitos Humanos: Os Mecanismos de Lock-in e Sinalização}

Diferentemente dos regimes internacionais que regulam áreas como comércio, finanças, meio ambiente e segurança, o foco principal dos regimes de direitos humanos não é regular externalidades surgidas de interações societais ao longo das fronteiras que podem afetar as relações interestatais; seu objetivo é, antes, o de responsabilizar os governos por atividades domésticas. Eles reconhecem direitos não dos Estados perante terceiros Estados, mas dos indivíduos perante seu próprio Estado. Além disso, a ação interestatal não é a única forma (e às vezes nem mesmo a principal) que leva ao seu acionamento. As comissões e cortes independentes ligadas ao regime internacional de direitos humanos são acionadas em muitos casos por queixas e ações individuais. Todas essas particularidades do regime internacional de direitos humanos colocam a questão de por que Estados, concebidos como atores racionais, ratificam tratados de direitos humanos que buscam limitar o exercício de seu poder soberano no âmbito doméstico.

Nos últimos anos, tem se desenvolvido uma literatura preocupada justamente com as razões e motivações que levam os governos a construírem e aceitarem os regimes internacionais de direitos humanos, cujas considerações nos são de interesse particular para entender as mudanças na política externa mexicana de direitos humanos durante o governo Fox. A hipótese oferecida por esses trabalhos é a de que existe uma associação entre a democratização do país e o aumento no grau de compromissos e acordos internacionais por ele assumidos no campo dos direitos humanos (MORAVCSIK, 2000; MANSFIELD; PEVEHOUSE, 2006; 2008; HAFNER-BURTON et al., 2008). A variá- 
vel regime político pode afetar, assim, segundo esses trabalhos, a propensão dos Estados a entrar em regimes de direitos humanos.

A lógica e os argumentos expostos por esta literatura têm duas vertentes. De um lado, estão os chamados mecanismos de tipo lock-in (trancamento) em contextos de transição democrática; de outro, salienta-se a necessidade dos regimes recém-democratizados de sinalizar para audiências domésticas e internacionais seu real compromisso para com as reformas e o avanço democrático. A ideia básica do mecanismo de lock-in, em primeiro lugar, é a de que o comprometimento internacional do Estado pode ter importantes efeitos sobre as dinâmicas da política doméstica. Os atores políticos domésticos podem, portanto, valer-se disso em vista dos seus interesses para consolidar seus resultados preferidos de políticas, em especial em momentos de transição democrática, que são momentos de alta incerteza quanto às futuras regras do jogo e aos resultados finais do processo.

A aceitação de compromissos internacionais vinculantes implica contrair obrigações internacionais que atam as mãos de futuras lideranças, diminuindo, assim, as chances de retrocessos democráticos - a reversão das políticas adotadas torna-se mais improvável, dados os custos de reputação, prestígio, entre outros, associados ao desrespeito das normas internacionais. Busca-se estabilizar, desse modo, políticas públicas, conferindo-lhes rigidez estrutural e tornando, portanto, mais difícil a mudança de práticas e obrigações no futuro. Recorre-se ao âmbito externo, nesse sentido, com o objetivo de salvaguardar e aprofundar as mudanças democráticas obtidas. A participação de governos de países que passam por processos de transição democrática em regimes internacionais de direitos humanos deve ser entendida, por conseguinte, como um recurso utilizado pelas novas lideranças políticas para a obtenção de apoio externo diante de desafios domésticos colocados à institucionalização das reformas democráticas.

Moravcsik (2000) argumenta que governos democráticos relativamente recentes e não consolidados podem buscar a participação em regimes internacionais de direitos humanos para obterem apoio externo perante desafios domésticos. Segundo ele, "comprometimentos institucionais internacionais são, como os comprometimen- 


\section{A Política Externa Mexicana de Direitos Humanos du-}

rante o Governo Fox ...

tos institucionais domésticos, mecanismos autointeressados para o 'trancamento' (locking in) de certas políticas domésticas preferidas [...] em face da futura incerteza política” (MORAVCSIK, 2000, p. 226). Como as situações de transição política são incertas no que se refere aos seus resultados, o incentivo para reduzir a incerteza política futura explica por que os atores governamentais estão dispostos em situações como essas a delegar parte de sua autoridade para uma entidade internacional: em troca da redução da incerteza política doméstica, os governantes estariam dispostos a suportar os custos de soberania envolvidos.

Quanto mais fortes os desafios internos que possam ameaçar a estabilidade política democrática recém-adquirida, maiores serão os benefícios da redução da incerteza política propiciada pelos regimes internacionais. Isso aumenta a tolerância dos governos perante os custos de soberania e de perda de discricionariedade estatal no momento em que fazem o cálculo entre aceitar ou não o regime. Dessa forma, os governos escolherão esta tática quando os benefícios ligados à redução da incerteza política futura superarem os custos de soberania dos compromissos internacionais. Diante da potencialidade ou existência de fato de oposição doméstica a uma dada política ou conjunto de políticas preferidas pelos tomadores de decisão-chave, eles podem recorrer a arranjos cooperativos internacionais que comprometam o país a cumprir tais políticas, consolidando, assim, seus resultados preferidos, que ficam "trancados". É em razão disso tudo que os regimes democráticos recém-estabelecidos - justamente os que têm maior interesse e preocupação em estabilizar e blindar o status quo político doméstico contra ameaças não democráticas - são os que mais buscarão fortalecer e se engajar com o regime internacional de direitos humanos.

Nesse sentido, o comprometimento com as normas de direitos humanos pode ser entendido como a expressão do interesse dos governos democráticos recém-estabelecidos de utilizar o âmbito internacional com o objetivo de que isso venha a funcionar como um constrangimento sobre possíveis futuros governos não democráticos ou mesmo governos eleitos democraticamente, mas que venham a desejar a subversão da democracia. Os constrangimentos internacionais, sejam eles dotados de capacidade de 
enforcement ou de natureza mais simbólica, funcionam, ainda que em distintos graus, como aliados para os atores domésticos que os ajudam a prevenir a ocorrência de rupturas e/ou retrocessos da ordem democrática. Nas palavras de Moravcsik (2000, p. 228), "esse comprometimento de dois níveis ata as mãos de futuros governos, de modo a aumentar a credibilidade das políticas e instituições domésticas em curso”.

Mansfield, Pevehouse (2006; 2008) e Hafner-Burton et al. (2008) também salientam que em processos de transição democrática os líderes do governo podem buscar obrigações internacionais para, com isso, atar as mãos de futuras lideranças e trancar as políticas liberais, em acordo com o mecanismo de lock-in. Mas, além disso, expõem outro mecanismo causal, o de sinalização, que pode motivar Estados em contextos de transição democrática a buscar maior comprometimento com o regime internacional de direitos humanos. Nesse sentido, as recém-estabelecidas democracias buscam maior comprometimento com o regime também para sinalizar de maneira crível sua intenção de consolidar instituições e práticas democráticas.

Para os autores, o sucesso da consolidação democrática depende da crença do público doméstico e internacional de que as reformas e o compromisso das novas lideranças com relação a elas são realmente genuínos, e não apenas compromissos vazios (cheap talk), mas o problema seria o de que em situações de transição democrática os líderes podem encontrar problemas para provar de maneira crível seu real compromisso com esses objetivos. Uma das formas que os líderes de novas democracias encontram então para aumentar a confiabilidade de seus compromissos é a utilização da vinculação com os regimes de direitos humanos como um mecanismo que lhes permite sinalizar suas reais intenções de levar a cabo reformas e de aprofundar a consolidação democrática. Assim, buscam aumentar a credibilidade de seus compromissos para com o projeto de cristalização das instituições democráticas.

Expande-se, portanto, a ligação causal entre regimes em transição, por um lado, e o comprometimento com o regime de direitos humanos, por outro, para além do mecanismo de lock-in, de trancamento de políticas, e maior atenção é concedida à necessidade de os regimes em transição sinalizarem para as audiências domésticas e internacionais a confiabili- 
A Política Externa Mexicana de Direitos Humanos durante o Governo Fox ...

dade de seus compromissos para com o aprofundamento da recémcriada democracia. Segundo Mansfield e Pevehouse (2008, p. 270),

No transcorrer de uma transição democrática, os líderes estatais encontram problemas para estabelecer um compromisso crível de sustentar as reformas, pois eles podem se beneficiar de impedimentos à liberalização. A ausência de tal compromisso pode comprometer a transição democrática. Tornar-se membro de uma Organização Internacional (OI) [ou de outro mecanismo do regime internacional de direitos humanos] pode fortalecer e tornar pública a credibilidade dos compromissos dos líderes para com as reformas democráticas.

Os contextos de transição democrática são permeados, como já argumentamos, pela incerteza política, o que leva ao surgimento de problemas de duas naturezas para as democracias emergentes: por um lado, há a possibilidade de aparecimento de desafios domésticos antidemocráticos que podem levar a retrocessos ou regressões autoritárias. Nesse caso, as lideranças das democracias nascentes muitas vezes se valem de instrumentos internacionais para blindar políticas e a nova situação democrática, de acordo com a lógica do lock-in. Porém, além disso, a incerteza política dos contextos de transição gera ainda problemas de credibilidade para as lideranças das democracias emergentes, na medida em que os líderes podem encontrar problemas para provar de maneira crível para as audiências domésticas e internacionais seu real compromisso com as reformas democráticas.

Os problemas de credibilidade enfrentados por regimes em democratização e democracias recém-estabelecidas são, portanto, outro resultado da incerteza que acompanha processos de transição democrática, assim como a possibilidade de retrocessos autoritários. No entanto, nesse caso, os riscos que a incerteza traz consigo não são necessariamente exógenos ao governo em questão, i.e., não se trata tanto do 
temor de que futuras lideranças subvertam a nova ordem democrática, mas sim de problemas que as próprias lideranças pretensamente comprometidas com as reformas e consolidação democrática enfrentam e que tornam muitas vezes difícil para as audiências domésticas e internacionais acreditar nos seus objetivos de políticas e na confiabilidade de seu comprometimento para com o avanço democrático.

A questão é que, em certos casos, os líderes das democracias nascentes podem encontrar incentivos para limitar as reformas, consolidar seu poder pessoal ou o de seu grupo, e enfraquecer as instituições democráticas emergentes, com o que acabariam impedindo ou atrapalhando a consolidação democrática. O problema de credibilidade surge então porque, diante dessas possibilidades, nem as audiências domésticas, nem as internacionais podem ter certeza sobre o tipo de liderança com a qual estão lidando. Elas nunca estão inteiramente seguras sobre se os líderes no governo desejam sinceramente consolidar a democracia ou se o que eles procuram são outros objetivos, como incrementar seu poder pessoal. Desse modo, o comprometimento com um mecanismo internacional do regime de direitos humanos emite um sinal potente sobre o comportamento futuro e as intenções e preferências do governo que lhe ajuda a superar os problemas de credibilidade que enfrenta. Ele não só concede reconhecimento internacional para as novas democracias, como ainda permite demonstrar uma ruptura com práticas autoritárias do passado e a seriedade de suas intenções e objetivos.

Tanta incerteza que se traduz em problemas de credibilidade e confiabilidade é fruto de várias fontes. Em primeiro lugar, os governos podem até iniciar reformas, mas há a chance de que eles logo percebam não ter incentivos para terminá-las, sobretudo quando as reformas incompletas oferecem certos benefícios para grupos-chave (rents to key constituencies) ou quando elas criam instituições que solidificam ou ampliam as prerrogativas e poderes do líder. Diferentemente de regimes já estabelecidos, os governos em contextos de transição democrática não possuem um histórico ou uma reputação que demonstre seu apego aos compromissos que assumem, o que gera incertezas sobre a confiabilidade de seu com- 


\section{A Política Externa Mexicana de Direitos Humanos du-}

rante o Governo Fox ...

prometimento. Para piorar, durante muitas transições os novos grupos que ascendem ao poder alteram políticas e instituições para que elas se adéquem a seus objetivos, o que enfraquece ainda mais a credibilidade dos compromissos por eles assumidos posteriormente de não mudarem mais políticas e instituições no futuro.

Em segundo lugar, regimes em transição podem ter preferências temporalmente inconsistentes (time-inconsistent preferences). Segundo os autores: "Uma política ótima de um regime ex ante pode diferir de suas avaliações de política apropriada ex post. Os governos que ascendem ao poder com o objetivo de promover e sustentar a liberalização política podem concluir que existem incentivos para reverter as reformas" (MANSFIELD; PEVEHOUSE, 2006, p. 140). Ainda que esse problema não se limite apenas às novas democracias, a maior instabilidade de tais países e as maiores taxas de alterações de suas lideranças incrementam a probabilidade de reversões de políticas ex post. Aqui as lideranças das novas democracias se beneficiariam de um mecanismo internacional que aumente os custos de mudanças de políticas ex post, não apenas blindando as políticas contra possíveis desafios antidemocráticos, mas também atando as mãos do próprio governo contra o problema das preferências inconsistentes por ele enfrentado. Assim, mesmo que ele busque no futuro alterar as políticas, o comprometimento internacional tornará as mudanças mais custosas, aumentando as chances de que ele, governo, prossiga com as reformas e o avanço democrático. Isso, por seu turno, aumenta a credibilidade dos compromissos dos líderes das novas democracias.

Mas por que a questão da confiabilidade é tão importante para as lideranças das democracias emergentes? Para os regimes recémdemocratizados, assegurar a credibilidade de seus compromissos é uma preocupação tão importante a ponto de justificar a estratégia de sinalização (e também a de lock-in) porque um déficit nesse âmbito pode ocasionar diversos e sérios problemas para a democracia nascente, tanto no plano doméstico quanto no internacional. A esse respeito, Mansfield e Pevehouse (2006, p. 141) argumentam que

A inabilidade dos Estados em democratização de realizarem compromissos críveis pode gerar vá- 
rios problemas. As elites frequentemente desconfiam umas das outras no período transicional e temem que o novo regime não sirva aos seus interesses. De forma mais ampla, se a população não acreditar que os esforços anunciados de reforma política são sinceros, é pouco provável que ela apoie o novo regime. Essa falta de apoio da sociedade pode ameaçar a consolidação democrática. Alguns grupos podem se opor de forma ativa ao regime, até mesmo recorrendo a medidas violentas ou se aliando com outros grupos descontentes na sociedade. A falta de apoio societal também pode levar o governo a tomar ações que desafiam a democracia [...]. Em suma, como Whitehead argumenta, "se cada setor político concluir que o compromisso democrático do outro é pequeno, isso reduzirá a motivação de todos, e assim se perpetuará a condição de fragilidade”.

No que diz respeito ao plano externo, um déficit de credibilidade dos regimes recém-democratizados pode também gerar problemas. Os atores internacionais podem se preocupar com o comportamento de governos de democracias emergentes, devido ao temor de que tais regimes se tornem instáveis politicamente e comecem a se comportar de maneira imprevisível, passando por mudanças institucionais e de políticas não antecipadas. Se não houver um compromisso claro e crível com o avanço das reformas democráticas, atores como empresas transnacionais, instituições financeiras e organizações internacionais podem relutar em investir ou oferecer ajuda a tais regimes.

O comprometimento internacional com o regime de direitos humanos não se presta, portanto, apenas à estratégia do lock-in, de atar as mãos de futuras lideranças, estabelecendo cadeados que trancam certas políticas. O comprometimento tem um propósito dual, já que, além do seu efeito de trancamento, ele ainda envia um sinal que fornece informações sobre os objetivos de políticas das lideranças, distinguindo-as dos líderes que usam 


\section{A Política Externa Mexicana de Direitos Humanos du- rante o Governo Fox ...}

a retórica da reforma apenas para fins como acumular poder, sem de fato se engajar com o projeto democratizador. A esse respeito, Hafner-Burton et al. (2008) lembram que o pertencimento aos regimes de direitos humanos pode oferecer "informações às audiências internacionais sobre os objetivos de uma nova democracia, sinalizando para outros Estados, firmas multinacionais e movimentos sociais transnacionais seu compromisso com os direitos humanos” (HAFNER-BURTON et al., 2008, p. 6).

Como vimos, as audiências domésticas e internacionais têm razões para desconfiar dos líderes de novas democracias, já que eles não só não têm um histórico consolidado de respeito aos compromissos que assumem, como ainda podem ter preferências temporalmente inconsistentes e se beneficiar de políticas que impeçam a consolidação da democracia. A sinalização busca demonstrar, diante de tais problemas de credibilidade, que a intenção é séria, e procura convencer as audiências domésticas e internacionais de que não se trata apenas de cheap talk. Por outro lado, ao assumir um compromisso público com a reforma política e a consolidação da democracia, geram-se, ademais, custos de audiência e reputação que aumentam ainda mais os custos de reversão das políticas. A conclusão de um acordo internacional coloca a reputação de um Estado em transição sob a mira dos holofotes. Desrespeitar as obrigações internacionais pode danificar a reputação do governo, reduzir a confiança da sociedade nele e precipitar a oposição doméstica, mesmo quando a ruptura da obrigação não significa a aplicação de sanções contra o país (MANSFIELD; PEVEHOUSE, 2008, p. 274).

A entrada em um regime internacional por parte de um regime recémdemocratizado sinaliza, em suma, de maneira crível para audiências domésticas e internacionais, as intenções do governo de levar a cabo reformas e de respeitar os direitos humanos de seus cidadãos, o que lhe concede uma fonte de reconhecimento internacional. No entanto, Hafner-Burton et al. (2008) recordam que o processo de sinalização, diferentemente do lock-in, não depende da existência de custos de soberania para ser efetivo, o que faz com que mesmo a entrada em um regime com baixa capacidade de enforcement, como são os tratados de direitos humanos quando comparados com as organizações internacionais do mesmo tema, possa cumprir a tarefa de sinalização. 


\section{O Governo Fox: A Política Externa como Âncora e Sinal da Transição}

O governo Fox (2000-2006), inaugurador da alternância política na Presidência da República, consolidou as mudanças em curso na política externa de direitos humanos desde o governo Salinas, aplicando uma série de medidas que transformaram a questão dos direitos humanos em uma prioridade das relações exteriores do país. O México inaugurou uma agressiva política externa de direitos humanos sem precedentes em sua história, e tornou-se um dos principais aliados das ONGs transnacionais no avanço da agenda internacional no tema. Além disso, adotou uma ativa diplomacia nos principais fóruns internacionais, como a Comissão de Direitos Humanos da Organização das Nações Unidas (ONU) e a Assembleia Geral da Organização dos Estados Americanos (OEA).

Na Assembleia Geral da ONU e na Comissão de Direitos Humanos desta mesma organização, apresentou e copatrocinou diversas resoluções e iniciativas sobre direitos humanos dos trabalhadores migratórios, das pessoas com necessidades especiais, dos povos indígenas e das mulheres; ademais, impulsionou iniciativas sobre a necessidade de proteção dos direitos humanos na luta contra o terrorismo (SECRETARÍA DE RELACIONES EXTERIORES, 2005; MISIÓN PERMANENTE DE MÉXICO EN LA ONU, 2006). O México propôs, ainda, a Convenção Internacional sobre os Direitos das Pessoas com Deficiência, participou da elaboração do Protocolo Adicional da Convenção contra a Tortura e da Convenção para a Proteção de todas as Pessoas contra Desaparecimentos Forçados, e apoiou a formulação da Declaração das Nações Unidas sobre Direitos dos Povos Indígenas. Durante o processo de reforma do sistema de direitos humanos da ONU, em 2005, promoveu o fortalecimento do Alto Comissariado das Nações Unidas para os Direitos Humanos (ACNUDH) e participou ativamente das negociações sobre a criação e estabelecimento do novo Conselho de Direitos Humanos, defendendo a ideia de criar um mecanismo de revisão periódica da situação dos direitos humanos em todos os países.

Como reconhecimento do trabalho internacional do México no tema dos direitos humanos, o representante mexicano ante o Conselho, o 
A Política Externa Mexicana de Direitos Humanos durante o Governo Fox ...

embaixador Luis Alfonso de Alba, foi eleito por unanimidade seu primeiro presidente para o período 2006-2007. Já no âmbito da OEA, dentre as muitas iniciativas mexicanas, foi aprovada, em julho de 2004, sua proposta para o estabelecimento de um mecanismo de monitoramento do cumprimento, pelos Estados, da Convenção Interamericana para Prevenir, Sancionar e Erradicar a Violência contra a Mulher, conhecida como Convenção de Belém do Pará (SECRETARÍA DE RELACIONES EXTERIORES, 2005, p. 225).

Se, no passado, o regime priísta havia se utilizado do discurso nacionalista tradicional dos princípios de soberania interna e não intervenção com a finalidade de obter legitimidade interna, proteger-se de críticas externas contra a situação autoritária do país e também, em muitos momentos, para projeção externa, ${ }^{3}$ a alternância política e o simbolismo del cambio que atestavam a nova realidade democrática do México concederam ao governo Fox um grau inédito de legitimidade internacional. O governo dispunha então do que ficou conhecido como o bônus democrático, e a diplomacia do país passou a defender ativamente, de forma inédita, um discurso baseado na preeminência dos valores da democracia e direitos humanos. Como consequência dessa nova postura, assistiu-se, nesse período, à abertura e integração plena do México ao regime internacional de direitos humanos.

A intenção de conceder ao tema dos direitos humanos um lugar central na agenda da política externa foxista havia sido manifestada de forma clara desde o início do governo e, antes disso, já no período da campanha eleitoral. Esperava-se que a atividade internacional do México com esta temática produzisse um efeito semelhante ao que o Tratado de Livre Comércio da América do Norte (em inglês, North American Free Trade Agreement; em português (NAFTA)) e, antes disso, a entrada no Acordo Geral sobre Tarifas e Comércio (em inglês, General Agreement on Tariffs and Trade (GATT)) haviam gerado no âmbito econômico: comprometer o país com a mudança interna no exterior para assegurar a reforma doméstica em matéria de direitos humanos e democracia. O chanceler Jorge G. Castañeda (2001-2003) argumentava que a política externa não era apenas um resultado das mudanças e dinâmicas internas; ela podia funcionar, ademais, como 
uma causa fomentadora das mudanças domésticas, um instrumento que auxiliaria na consolidação de uma nova cultura e institucionalidade democráticas. O estímulo externo ajudaria a forçar uma mudança doméstica no âmbito das práticas insatisfatórias que os desrespeitavam, pondo em marcha no país a maquinaria dos direitos humanos.

A concepção sobre a vinculação entre a política externa e a doméstica e, além disso, o entendimento do papel que o âmbito externo poderia desempenhar perante o plano interno passavam, assim, por uma importante alteração. Até então, as prioridades da política externa para os governos do PRI estavam ligadas à tarefa de promover o desenvolvimento econômico e servir de dique de contenção às interferências externas em seus assuntos internos (GONZÁLEZ, 2006, p. 160). Com o governo Fox, no entanto, a política exterior ganhava um novo lugar e papel, relacionado, por um lado, com o processo de consolidação e construção institucional da nova democracia mexicana e, por outro, com a projeção da imagem de um país comprometido com a democracia e os direitos humanos.

A defesa dos direitos humanos como um dos objetivos centrais da política externa do governo Fox deve ser entendida, assim, dentro do contexto da democratização. As mudanças da política exterior de direitos humanos serviam, nesse contexto, a dois objetivos: por um lado, faziam parte de uma tentativa para sustentar e aprofundar, no exterior, a nova situação democrática doméstica por meio da aceitação de compromissos internacionais. A mudança de regime influenciava, portanto, a política externa no sentido de que a nova diplomacia do governo buscava ancorar no exterior a emergente democracia mexicana. Esta estratégia que procura impulsionar e salvaguardar reformas internas recorrendo ao âmbito externo e à vinculação com compromissos internacionais pode ser entendida a partir das contribuições da literatura sobre o mecanismo de lock-in (MORAVCSIK, 2000; MANSFIELD; PEVEHOUSE, 2006; 2008). Por outro lado, as mudanças e o maior comprometimento com as normas internacionais de direitos humanos buscavam ainda sinalizar de maneira crível para as audiências domésticas e internacionais a nova natureza (e imagem) do regime, bem como seu compromisso efetivo com o respeito aos direitos humanos e a consoli- 
A Política Externa Mexicana de Direitos Humanos durante o Governo Fox ...

dação democrática (HAFNER-BURTON et al., 2008; MANSFIELD; PEVEHOUSE, 2006; 2008), em contraposição ao passado priísta autoritário.

Após assumir a Presidência, ainda em 2000, Fox acabou com as restrições de visto de observadores de direitos humanos criadas durante o governo Zedillo, pondo fim às restrições ao escrutínio internacional que limitavam a entrada e movimentação de membros de ONGs internacionais no país. O governo assinou ainda um programa de cooperação técnica com o ACNUDH, a partir do qual se estabeleceria depois um escritório permanente do ACNUDH no México e um diagnóstico da situação dos direitos humanos no México, ${ }^{4}$ do qual resultaria, por fim, o Programa Nacional de Direitos Humanos, apresentado no final de 2004. A assinatura do acordo revestia-se de grande simbolismo não só por ser o primeiro ato de política externa do governo Fox, mas também porque era a concretização de uma antiga demanda das ONGs mexicanas de direitos humanos com a qual o governo Zedillo não havia se comprometido plenamente. ${ }^{5}$

Os primeiros atos do governo Fox no tema dos direitos humanos não se limitaram, no entanto, à aproximação e cooperação com o ACNUDH. As autoridades mexicanas apoiaram a inclusão de uma cláusula democrática na Declaração de Quebec, resultante da Terceira Cúpula das Américas, realizada em 2001, no Canadá, segundo a qual a participação dos Estados nas futuras cúpulas e seu pertencimento à ALCA estariam vinculados à manutenção de seus regimes democráticos. $\mathrm{Na}$ OEA, o governo assumiu uma posição semelhante ao apoiar a Carta Democrática Interamericana, aprovada em setembro de 2001 . $^{6}$

Outras decisões tomadas pelo governo também deixavam claras suas intenções de inaugurar uma nova política externa de direitos humanos que mudasse a imagem do México de um país problema, com uma situação difícil em direitos humanos, para a de um interlocutor válido no seio da comunidade das nações democráticas. O general José Francisco Gallardo foi libertado em 7 de fevereiro de 2002, depois de oito anos de prisão, em conformidade com recomendação da Comissão Interamericana de Direitos Humanos (CIDH), ${ }^{7}$ que já havia sugerido sua libertação em outubro de 1996; o empresário argentino Ricardo 
Miguel Cavallo foi extraditado para a Espanha por crimes cometidos durante o regime militar na Argentina, em 28 de junho de $2003 ;^{8}$ e os camponeses ecologistas Rodolfo Montiel e Teodoro Cabrera foram liberados da prisão em 7 de novembro de $2001 .^{9}$

Por fim, o governo estabeleceu uma política de abertura e convite permanente à visita de mecanismos internacionais de direitos humanos. No total, ao longo do governo Fox, o México recebeu a visita de dezessete representantes de mecanismos internacionais de direitos humanos, da ONU e da OEA, como aparece indicado na tabela abaixo.

Tabela 1

Histórico de Visitas de Mecanismos de Direitos Humanos durante o Governo Fox

Visitas

Mecanismos da ONU

1) Relator Especial da Comissão de Direitos Humanos da ONU (CDH) sobre a Independência de Juízes e Magistrados (13-23 de maio de 2001)

2) Comitê contra a Tortura (23 de agosto-12 de setembro de 2001)

3) Relator Especial sobre Moradia Adequada como um Elemento Integrante do Direito a um Nível de Vida Adequado (4-15 de março de 2002)

4) Relatora Especial sobre Direitos Humanos dos Migrantes (7-18 de março de 2002)

5) Representante do Secretário-geral para os Desalojados Internos (18-28 de agosto de 2002)

6) Presidente do Grupo de Trabalho sobre Detenção Arbitrária da $\mathrm{CDH}$ e a Especialista do Paraguai (27 de outubro-10 de novembro de 2002)

7) Relator Especial da CDH sobre a situação dos Direitos Humanos e das Liberdades Fundamentais dos Indígenas (2-13 de julho de 2003)

8) Visita Confidencial das Especialistas do Comitê para a Eliminação da Discriminação contra a Mulher (19-25 de outubro de 2003)

9) Missão de Especialistas Internacionais da Oficina das Nações Unidas contra a Droga e o Delito a Ciudad Juárez, Chihuahua (outubro de 2003)

10) Relatora Especial sobre a Violência contra a Mulher, suas Causas e Consequências (2125 de fevereiro de 2005)

Mecanismos da OEA

11) Presidente da CIDH (2-5 de julho de 2001)

12) Relatora Especial de Assuntos da Mulher (9-12 de fevereiro de 2002)

13) Relator Especial para os Trabalhadores Migratórios da CIDH (25-31 de julho de 2002)

14) Relator sobre Liberdade de Expressão (18-26 de agosto de 2003)

15) Relator Especial para México e sobre os Direitos dos Povos Indígenas da CIDH (24-31 de agosto de 2005)

ACNUDH

16) Alta Comissária das Nações Unidas para Direitos Humanos, Mary Robinson (2 de dezembro de 2000)

17) Alta Comissária das Nações Unidas para Direitos Humanos, Mary Robinson (30 de junho-2 de julho de 2002)

Fonte: Elaboração própria, com base em Naciones Unidas (2008) e Misión Permanente de México en la ONU (2006). 
A Política Externa Mexicana de Direitos Humanos durante o Governo Fox ...

Além da permissão aberta às visitas de membros de ONGs internacionais de direitos humanos, e dos convites aos representantes dos mecanismos internacionais nessa matéria para que fossem ao México, o governo mexicano assinou e ratificou uma série de tratados internacionais de direitos humanos; reconheceu a competência dos comitês ligados aos tratados do sistema de direitos humanos da ONU no que diz respeito ao recebimento de queixas de indivíduos; e retirou algumas reservas feitas anteriormente pelos governos do PRI ao texto de certos acordos. Ao todo, o governo mexicano ratificou sete instrumentos jurídicos, aderiu a três mecanismos na matéria, retirou duas reservas a tratados e aceitou uma emenda a uma convenção de direitos humanos, em um total de treze alterações com respeito ao seu vínculo com os instrumentos jurídicos internacionais de direitos humanos, conforme se apresenta na tabela abaixo.

Tabela 2

Vinculação com Instrumentos Jurídicos Internacionais de Direitos Humanos durante o Governo Fox

Tratados Ratificados pelo Governo Fox

1) Convenção Interamericana sobre Desaparecimento Forçado de Pessoas - Ratificação em 9 de abril de 2002

2) Convenção sobre a Imprescritibilidade dos Crimes de Guerra e dos Crimes de Lesa Humanidade - Ratificação em 15 de março de 2002

3) Protocolo Facultativo da Convenção sobre os Direitos da Criança relativo à Participação de Crianças em Conflitos Armados - Ratificação em 15 de março de 2002

4) Protocolo Facultativo da Convenção sobre os Direitos da Criança relativo à Venda de Crianças, Prostituição Infantil e Utilização de Crianças em Pornografia - Ratificação em 15 de março de 2002

5) Protocolo Facultativo da Convenção contra a Tortura e outros Tratamentos ou Penas Cruéis, Desumanos ou Degradantes - Ratificação em 11 de abril de 2005

6) Estatuto de Roma do Tribunal Penal Internacional - Ratificação em 28 de outubro de 2005

Instrumentos que Implicavam o Reconhecimento da Competência de Receber Comunicações Individuais por parte dos Mecanismos Ligados aos Tratados

7) Protocolo Facultativo da Convenção sobre a Eliminação de todas as Formas de Discriminação contra a Mulher - Ratificação em 15 de março de 2002

8) Primeiro Protocolo Facultativo do Pacto Internacional de Direitos Civis e Políticos Adesão em 15 de março de 2002

9) Declaração de Reconhecimento por parte do México da Competência do Comitê para a Eliminação da Discriminação Racial, estabelecido pela Convenção Internacional sobre a Eliminação de todas as formas de Discriminação Racial, em conformidade com o artigo 14 da Convenção - Adesão em 15 de março de 2002 
10) Declaração de Reconhecimento por parte do México da Competência do Comitê contra a Tortura, estabelecido pela Convenção contra a Tortura e outros Tratamentos ou Penas Cruéis, Desumanos ou Degradantes, em conformidade com o artigo 22 da Convenção - Adesão em 15 de março de 2002

Retirada de Reservas e Aceitação de Emendas

11) Retirada Parcial da Reserva ao artigo 25-b do Pacto Internacional de Direitos Civis e Políticos (voto ativo dos ministros de culto)

12) Retirada Parcial da Declaração Interpretativa e da reserva à Convenção Americana sobre Direitos Humanos (voto ativo de ministros de culto e celebração de atos públicos de culto religioso)

13) Emendas aos artigos 17 (7) e 18 (5) da Convenção contra a Tortura e outros Tratamentos ou Penas Cruéis, Desumanos ou Degradantes - Aceitação em 15 de março de 2002

Fonte: Elaboração própria, com base em Secretaría de Relaciones Exteriores (2005), Informe de Ejecución del PNDH 2005 (2005), Human Rights Watch (2006) e Mecanismo de Búsqueda de Tratados de la SRE (http://www.sre.gob. mx/tratados /Default.htm).

Outra medida que demonstrava a nova atitude do governo diante do tema dos direitos humanos foi a criação, ainda em 2001, da Fiscalía Especial para Movimientos Sociales y Políticos del Pasado (FEMOSPP), encarregada das investigações das violações aos direitos humanos cometidas durante os massacres estudantis de 1968, 1971 e também durante a guerra suja mexicana. ${ }^{10}$ Em seu informe 26/2001, apresentado em 27 de novembro de 2001, a Comissão Nacional dos Direitos Humanos (CNDH) informou, com base em 532 queixas recebidas sobre casos de desaparecimento forçado, que durante a década de 1970 e início dos anos 1980, os anos da chamada "guerra sucia", era possível comprovar 275 casos plenamente documentados de desaparecimentos forçados de que haviam participado autoridades estatais. ${ }^{11}$ Para atender às recomendações desse informe, os arquivos dos organismos de segurança do Estado relativos a essa época foram abertos, e foram criados a FEMOSPP e um comitê institucional de reparação dos danos às vítimas presidido pela Secretaria de Gobernación, vigente até hoje. ${ }^{12}$

Ainda em 2001, foi criada a Unidade de Defesa e Promoção de Diretos Humanos dentro da Secretaria de Gobernación (Segob), cuja criação "resultou de uma demanda explícita de ONGs nacionais no contexto da intensa pressão internacional e nacional depois da morte da ativista de direitos humanos Digna Ochoa"13 (ANAYA, 2009, p. 51). Mas tal medida não era resultado apenas da pressão de organizações da sociedade civil. Era parte, ademais, de uma política mais ampla do governo, já que 


\section{A Política Externa Mexicana de Direitos Humanos du-}

rante o Governo Fox ...

outros órgãos especializados em direitos humanos foram criados a partir de 2001 não só na Secretaria de Gobernación e na Secretaria de Relações Exteriores, mas também na Secretaria de Segurança Pública e na Procuradoria Geral da República (PGR).

Entretanto, as mudanças organizacionais que envolviam as diversas secretarias governamentais de forma mais profunda no tema dos direitos humanos não parariam por aí, já que o governo Fox também estabeleceu a Comissão de Política Governamental em Matéria de Diretos Humanos, em 2003. A Comissão era composta por membros de várias secretarias e agências governamentais sob liderança da Secretaria de Gobernación (Segob), "com o objetivo de introduzir os direitos humanos no desenho e implementação de políticas públicas” (ANAYA, 2009, p. 42). Seu objetivo era criar um espaço para coordenar as ações em matéria de direitos humanos das várias dependências e secretarias da administração pública federal (SECRETARÍA DE RELACIONES EXTERIORES, 2005, p. 144). Ela substituía a Comissão Intersecretarial para a Atenção dos Compromissos Internacionais do México em Matéria de Direitos Humanos que havia sido criada pelo governo Zedillo, em 1997, para confrontar o desafio colocado pela deterioração da imagem e reputação do país no contexto do conflito em Chiapas. ${ }^{14}$ Sua presidência passou a ser exercida pela Segob, e não mais pela Secretaria de Relações Exteriores (SRE), como ocorrera anteriormente, em parte como uma resposta a uma antiga insistência das ONGs mexicanas que defendiam que ela deveria ser presidida pela secretaria que se encarregava dos assuntos internos do país, e não pela dependência que se ocupava da política externa (MAZA, 2008, p. 46-47). ${ }^{15}$

Esses são apenas alguns exemplos de um número muito mais extenso de medidas adotadas pelo governo Fox que refletem como ele aprofundou as mudanças na política externa de direitos humanos que, embora de forma lenta e gradual, já vinham sendo tomadas pelos dois últimos governos do PRI, dos presidentes Salinas e Zedillo. No entanto, essa mudança é explicada pelo argumento aqui proposto ou ela foi causada pela pressão da rede transnacional de direitos humanos, como havia ocorrido nos dois últimos governos priístas? Abaixo apresento dados sobre as comunicações do exterior recebidas pela CNDH durante os três governos citados como um indicador da evolução da pressão da rede transnacional de ativismo em direitos 
humanos sobre o governo do México para avaliar se ela pode ter sido responsável pelas mudanças da política externa. Por meio dessas comunicações, as ONGs internacionais e outros grupos estrangeiros expressam suas preocupações, dúvidas e críticas sobre a situação dos direitos humanos no país. Elas são, desse modo, uma espécie de termômetro que mede a atenção dispensada pela rede transnacional de direitos humanos para o caso mexicano ao longo dos anos.

\section{Gráfico 1}

Número de Comunicações do Exterior Recebidas pela CNDH - "Termômetro" da Atuação da Rede Transnacional

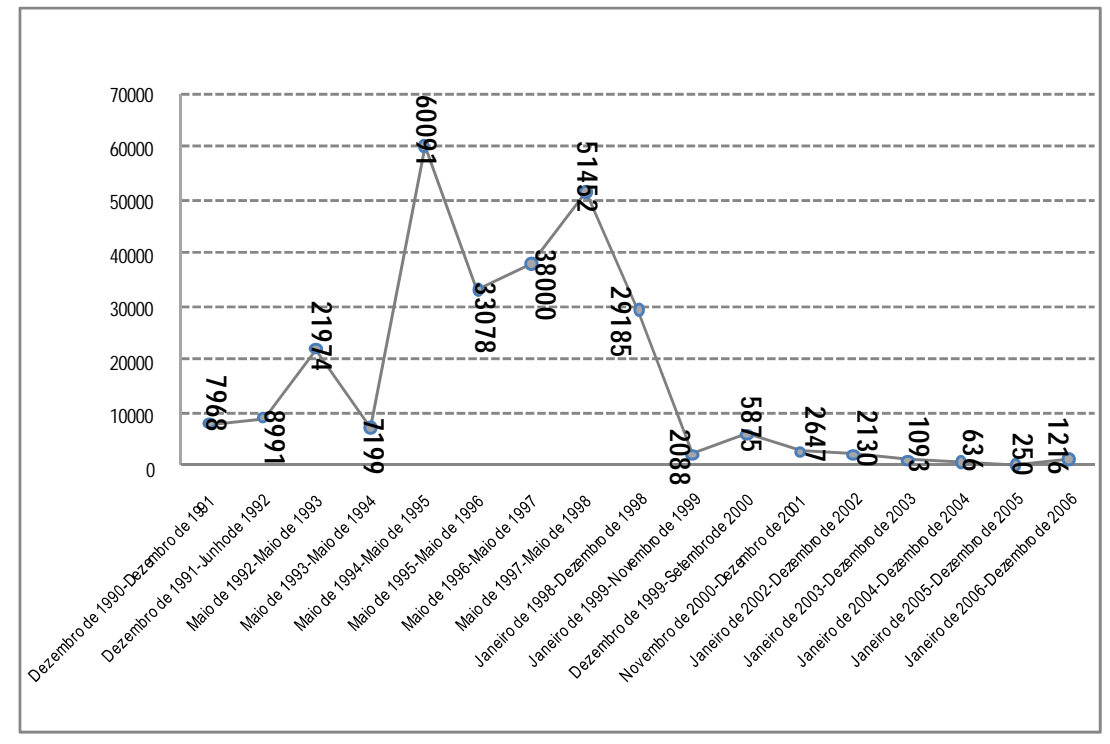

Fonte: Informações obtidas pelo autor por meio do Sistema de Acceso a la Información (SISAI) da Comissão Nacional de Direitos Humanos (CNDH) em dezembro de 2008.

Como pode ser observado, os momentos de maior atuação da rede transnacional de direitos humanos estão concentrados durante a negociação do NAFTA, especialmente no período de maio de 1992 a maio de 1993, quando a CNDH recebeu 21.974 comunicações do exterior, e depois do surgimento do levante zapatista. Nesse caso, dois momentos foram mais significativos: quando o movimento surgiu, em 1994, e a CNDH recebeu 60.091 comunicações do exterior entre maio de 1994 e maio de 1995, e depois do massacre de Acteal, ocorrido em 22 de 
A Política Externa Mexicana de Direitos Humanos durante o Governo Fox ...

dezembro de 1997, quando a CNDH recebeu 51.452 comunicações entre maio de 1997 e maio de 1998.

Outro ponto mostrado pelos dados é que, de fato, como apontam a literatura (MAZA, 2008, p. 45; WHITEHEAD, 2008, p. 386; ANAYA, 2009, p. 50) e os ativistas mexicanos de direitos humanos, ${ }^{16}$ houve uma queda significativa da atividade da rede transnacional de direitos humanos para o caso mexicano durante o governo Fox. A diminuição da pressão transnacional foi causada pela nova legitimidade internacional do governo Fox (seu bônus democrático), e pela nova política externa mexicana que abriu o país definitivamente à observação internacional e passou a defender firmemente os direitos humanos nos principais fóruns internacionais.

Como Maza (2008) argumenta, as ONGs mexicanas que insistiam na necessidade de continuar com a pressão internacional ouviram de muitos de seus aliados internacionais (ONGs e governos) que eles não pressionariam o governo Fox como haviam feito durante o governo Zedillo, pois era necessário dar tempo ao novo governo, que não poderia alterar a situação de direitos humanos do México tão rapidamente como esperavam as ONGs mexicanas depois da hegemonia priísta de 71 anos (MAZA, 2008, p. 45; entrevista pessoal com Alfonso García em 27 de outubro de 2008). ${ }^{17}$ Além disso, o México deixava de ser, com sua nova política externa de direitos humanos, parte do problema para se tornar parte da solução nos fóruns internacionais de direitos humanos (ANAYA, 2009, p. 50). Assim, por conta das dificuldades de seguir operando no âmbito da rede transnacional, e também devido ao voto de confiança que muitas ONGs resolveram conceder ao novo governo, o trabalho internacional das ONGs mexicanas foi redirecionado para o âmbito nacional, especialmente para atividades que envolviam o acompanhamento e participação nas diferentes fases do acordo de cooperação técnica com o ACNUDH (MAZA, 2008, p. 45-46). O ativismo e a participação das ONGs mexicanas em Genebra, na ONU, e na OEA diminuíram consideravelmente. ${ }^{18}$

A rede transnacional de direitos humanos foi ativada em casos específicos ao longo do governo Fox, como nos casos dos homicídios de mulheres em Ciudad Juárez e da morte da ativista de direitos humanos 
Digna Ochoa. Todavia, o grau de atividade da rede nesses casos foi bem menor em comparação ao momento em que as pressões haviam atingido seu ponto mais alto durante o governo Zedillo. No entanto, apesar da falta de pressão da rede transnacional, a "pressão (de fato ou potencial) continuou a importar durante os primeiros anos da década de 2000, já que os funcionários do governo queriam evitar que o México se tornasse novamente alvo da diplomacia de shaming, como havia ocorrido durante a Presidência de Ernesto Zedillo" (ANAYA, 2009, p. 50).

Assim, a preocupação com a pressão potencial e com a reputação do México continuava a ser importante para o governo, e a política externa continuou a ser influenciada pela perspectiva da pressão da rede transnacional de direitos humanos. No entanto, se antes os governos Salinas e Zedillo respondiam ou se antecipavam às pressões e campanhas de shaming da rede transnacional com concessões táticas para demonstrar que o país se preocupava com o tema das violações e estava comprometido a investigá-las e julgar os culpados, aqui o governo Fox, mesmo diante das baixas chances de sofrer pressão, alterou substancialmente posturas tradicionais da política externa mexicana de direitos humanos. É claro que os tomadores de decisão não queriam que o México se tornasse uma vez mais alvo da rede transnacional, mas a causa principal das mudanças estava no interesse subjacente do governo que havia mudado substancialmente.

Agora o regime buscava sinalizar para audiências domésticas e internacionais seu real compromisso com as reformas e o avanço democráticos com o objetivo de alterar a imagem internacional do país associada com os governos priístas. A possibilidade da pressão da rede continuava importante, mas a causa principal das mudanças, como a decisão dos votos contra Cuba na Comissão de Direitos Humanos da $\mathrm{ONU}^{19}$ e a abertura total ao escrutínio internacional, era, em primeiro lugar, para sinalizar para a comunidade internacional que a nova abordagem do governo era séria, construindo assim uma nova imagem para o país de defensor dos direitos humanos. Além disso, as mudanças buscavam ancorar a nova situação democrática com compromissos internacionais de direitos humanos. A preocupação com a imagem do 


\section{A Política Externa Mexicana de Direitos Humanos du-}

rante o Governo Fox ...

país e com as possíveis críticas internacionais continuou importante, mas as mudanças já não ocorriam como reações a pressões externas, como no passado. As mudanças agora eram desenhadas endogenamente pelo governo mexicano e cumpriam objetivos delineados pelo próprio governo Fox.

De acordo com Jorge Castañeda em entrevista pessoal em 22 de novembro de $2008,{ }^{20}$ a ideia do governo Fox de ancorar a situação doméstica no exterior por meio de compromissos internacionais de direitos humanos esteve permeada pelo temor de um possível retrocesso autoritário e foi resultado da combinação da influência de três processos prévios. Em primeiro lugar, a tradição de atuação do PAN iniciada durante os conflitos eleitorais de 1985 e 1986 de recorrer a mecanismos internacionais de direitos humanos para combater as fraudes eleitorais. Em segundo lugar, o histórico de ativismo de líderes cívicos durante os anos 1990 (Mariclaire Acosta, Adolfo Aguilar Zinser, Jorge G. Castañeda, Sergio Aguayo, Santiago Creel), que também se haviam acostumado a recorrer a instâncias internacionais para denunciar violações aos direitos humanos e tentavam incluir em acordos internacionais como o NAFTA cláusulas de direitos humanos e/ou de democracia. ${ }^{21} \mathrm{E}$, por fim, em terceiro lugar, o papel das conversas de Vicente Fox, Jorge G. Castañeda, Adolfo Aguilar Zinser e, em menor medida, Santiago Creel com Felipe González, ex-presidente do governo espanhol (1982-1996) que sempre sustentou que a entrada espanhola na Comunidade Econômica Europeia e na OTAN havia servido como âncora externa da democracia espanhola. ${ }^{22}$

O governo Fox entendia que era necessário consolidar a transição democrática do país, e que as instituições e normas internacionais, entre elas as relacionadas com a proteção e promoção dos direitos humanos, tinham um papel-chave nesse processo. Mas não se tratava apenas de ancorar a transição democrática no exterior, pois, na verdade, o lock-in só seria possível e consequente se o novo governo conseguisse construir uma nova imagem internacional do México como defensor dos direitos humanos e democracia, provando ser coerente e consistente com suas novas ações. Como nota Castañeda, antes de conseguir a visita de relatores de direitos humanos para o México e de 
usá-los como âncoras externas para a consolidação democrática, o governo precisava sinalizar de maneira convincente que as mudanças eram sérias e que o México tinha uma nova política externa congruente com a democracia e direitos humanos que se aplicava a todas as relações exteriores do país, mesmo para aqueles temas sensíveis e tradicionais como a posição assumida com relação a Cuba. Assim, os objetivos de lock-in e de sinalização, nesse caso para a construção de uma nova imagem internacional, estavam intimamente relacionados, e motivaram de forma conjunta as mudanças da política externa mexicana durante o governo Fox.

No entanto, Anaya (2009, p. 57) defende que

[...] o fato de que o governo Fox fosse democrático, por si só, não explica a adoção de uma nova abordagem de direitos humanos. Essa nova abordagem é explicada pelas crenças de certos tomadores de decisão de que os ganhos democráticos pudessem ser revertidos e de que as normas e instituições internacionais poderiam ser instrumentais para dar segurança ao novo contexto político.

Segundo esse argumento, a causa das mudanças da política externa mexicana de direitos humanos reside em última instância nas crenças dos principais tomadores de decisão, e não na variável transição à democracia.

As crenças e convicções dos principais tomadores de decisão certamente desempenham um papel importante na explicação das mudanças da política externa, mas é importante frisar que a decisão dos líderes de fazer o lock-in externo depende também de incentivos oferecidos pelo contexto político doméstico no qual esses tomadores de decisão estão inseridos, e de um cálculo mais instrumental entre custos e benefícios. A estratégia de lock-in implica, no geral, custos de soberania e traz novos constrangimentos à ação internacional do país, de forma que a decisão de ancorar a nova situação democrática no exterior não é influenciada apenas pelo papel das crenças e convicções das 


\section{A Política Externa Mexicana de Direitos Humanos du-}

rante o Governo Fox ...

lideranças, mas também por cálculos mais estratégicos referentes aos custos e benefícios esperados dessa decisão.

No caso mexicano, em particular, a estratégia não só envolvia custos externos de vínculo com as obrigações internacionais, mas também gerava tensões nas relações bilaterais, sobretudo com Cuba, e ainda custos internos, pois levou à politização da política externa, à utilização da temática para fins eleitorais e a enfrentamentos do governo com a oposição doméstica. No momento da decisão sobre a estratégia de lock-in, não apenas as crenças exerceram um papel. Além delas, foram pesados os custos supracitados e os benefícios que se esperava com o "ancoramento": consolidar a recém-democracia, tornando mais custosa uma regressão autoritária, e sinalizar uma nova imagem democrática do governo. A questão não pode ser reduzida, por conseguinte, apenas ao papel das crenças. As crenças e convicções precisam, nesse sentido, ter um mínimo de correlação com o contexto macropolítico no qual os tomadores de decisão se encontram para que os benefícios da estratégia superem seus custos, tornando-a a opção mais racional de ser adotada.

Os tomadores de decisão podem nutrir uma crença sobre o papel positivo das normas internacionais, oriunda, inclusive, de seu passado prévio de ativismo no âmbito da sociedade civil, mas, se o contexto político doméstico não oferecer incertezas sobre o futuro da jovem democracia, é mais provável que eles não encontrem tantos incentivos para se comprometerem internacionalmente. Empiricamente, tal argumento foi demonstrado por Moravcsik (2000), Mansfield e Pevehouse (2006; 2008) e Hafner et al. (2008), que mostram como democracias estabelecidas há mais tempo, nas quais se espera que os valores democráticos e de direitos humanos estejam mais consolidados, têm menor propensão de aceitarem compromissos internacionais vinculantes nessas matérias, justamente porque os custos associados da estratégia não valem a pena para essas sociedades onde as incertezas políticas já são bastante reduzidas.

Desse modo, a decisão de adotar a estratégia de lock-in é influenciada pelos incentivos oferecidos pelo contexto político doméstico, em especial pelo grau de incerteza do processo político que é função da posição rela- 
tiva do novo governo em comparação com a oposição que no passado esteve associada com o regime autoritário. A incerteza sobre o resultado final do processo de transição e os incentivos dos líderes de recorrerem ao ancoramento da nova situação democrática no exterior crescem de acordo com a força relativa da oposição perante o governo - quanto mais forte a oposição, mais incerto o contexto político doméstico e mais provável que o governo recorra à estratégia de lock-in.

No ano 2000, quando da chegada à Presidência de Vicente Fox, havia uma incerteza significativa sobre o futuro político do país e até mesmo um temor sobre a possibilidade de uma regressão, já que o PRI continuava a ser uma força política bastante poderosa capaz de reverter muitos dos ganhos democráticos recentes do México. Se a situação democrática recente sozinha não explica as mudanças da política externa de direitos humanos, as crenças e convicções dos tomadores de decisão, tampouco. Apesar da crença de alguns membros do governo Fox de que os regimes internacionais de direitos humanos poderiam ajudar a consolidar a democracia, a decisão de adotar a estratégia de lock-in só fazia sentido porque havia esse contexto político doméstico marcado por um grau considerável de incerteza que tornava os benefícios do ancoramento no exterior superiores aos custos desse novo tipo de política externa.

\section{Considerações Finais}

Neste artigo defendemos o argumento de que a política externa mexicana de direitos humanos do governo Fox e as mudanças de práticas e políticas domésticas que a acompanharam podem ser explicadas por cálculos endógenos ao próprio governo que com elas buscava ancorar a transição democrática no exterior e sinalizar a credibilidade e seriedade de suas credenciais democráticas.

A decisão do governo Fox de ancorar no exterior a nova situação democrática e de sinalizá-la para audiências externas e domésticas por meio de compromissos internacionais e de uma nova política externa de direitos humanos foi motivada de maneira decisiva pelas crenças e 


\section{A Política Externa Mexicana de Direitos Humanos du-}

rante o Governo Fox ...

experiência prévia dos tomadores de decisão, muitos dos quais eram egressos do ativismo no âmbito da sociedade civil.

Entretanto, é importante observar que o lock-in apenas se torna uma estratégia razoável que os líderes passam a considerar seriamente se o contexto político no qual eles estiverem inseridos oferecer incentivos - na forma de riscos potenciais de um retrocesso político que eles buscam evitar - que façam os custos da estratégia serem inferiores aos benefícios esperados. Assim, mesmo as crenças de tomadores de decisão-chave de que os ganhos democráticos podiam ser ameaçados, e o poder apelativo desse argumento para audiências mais amplas, estavam intimamente vinculados com a existência prévia de um contexto político marcado pela incerteza política, como o do México quando o PRI viu ruir em definitivo a sua hegemonia política de 71 anos sobre o país em 2000.

Desse modo, vê-se novamente como a democratização afeta o resultado final, as mudanças na política externa mexicana de direitos humanos. As mudanças e a decisão da nova elite política que ascendeu à Presidência em 2000 de ancorar no exterior a recente democracia mexicana não podem ser explicadas sem referência à natureza específica do processo de democratização no México. Tal processo não resultou no desaparecimento do antigo partido autoritário que, pelo contrário, continuou muito forte politicamente. Sua permanência no cenário político gerou um contexto marcado por um grau significativo de incerteza, no qual a tese do lock-in fazia muito mais sentido. É certo que as crenças existiam, mas a sua própria existência era parte, e dependia, em boa medida, deste processo maior que conformava a transição democrática no país. Nesse sentido, a adoção de compromissos pelo governo Fox só pode ser entendida se levados em conta os cálculos da nova elite dentro do contexto transicional em que as incertezas e problemas de credibilidade a levaram a buscar o ancoramento externo. 


\section{Notas}

1. Um sistema de partido hegemônico é definido aqui como "o exercício virtual de um monopólio político por parte de um partido que, no entanto, coexiste no cenário político com partidos de oposição legalmente registrados” (CRESPO, 1998, p. 21). (Esta e as demais citações de originais estrangeiros foram aqui livremente traduzidas.) Nesse sistema, o partido hegemônico possui uma vinculação orgânica com o Estado, o que supõe que o aparato estatal lhe concede vultosos e decisivos recursos para a sua preservação no poder.

2. Tais reformas fizeram com que o Instituto Federal Eleitoral (IFE), responsável pela organização das eleições, deixasse de ser vinculado ao Executivo federal, tornando-se uma instituição autônoma.

3. A defesa dos princípios de não intervenção, autodeterminação e soberania interna, plasmados nas Doutrinas Carranza e Estrada, frisava o caráter independente e autônomo da política externa mexicana em relação aos Estados Unidos e ao conflito Leste-Oeste, em consonância com a natureza "revolucionária” do regime. A relação do México para com o regime revolucionário cubano e o Chile de Allende era emblemática nesse sentido.

4. Oficina del Alto Comisionado para los Derechos Humanos en México. Diagnóstico sobre la situación de los derechos humanos en México. México, 2003. Disponível em: <http://www.sre.gob.mx/derechoshumanos/docs/Diagnostico. pdf $>$. Acesso em: 22 jun. 2009.

5. As ONGs mexicanas de direitos humanos, inspiradas na estratégia adotada por ONGs colombianas, haviam feito lobby no âmbito da Comissão de Direitos Humanos da ONU durante o governo Zedillo para que fosse aprovada uma resolução que forçasse o México a negociar o estabelecimento de um escritório do Alto Comissariado das Nações Unidas para Direitos Humanos em seu território. No entanto, o governo Zedillo apenas assinou um memorando de intenção para o estabelecimento de um programa de cooperação técnica com o ACNUDH.

6. Além do ativismo no âmbito da OEA, o governo Fox contribuiu também economicamente com o sistema interamericano de direitos humanos. Além das contribuições orçamentárias tradicionais à OEA, o governo Fox passou a oferecer desde 2001 fundos extra, voluntários, para a Comissão Interamericana de Direitos Humanos (CIDH) e a Corte Interamericana de Direitos Humanos. O governo mexicano destinou, desde 2001, somente para a CIDH, 100 mil dólares anuais 


\section{A Política Externa Mexicana de Direitos Humanos du-}

rante o Governo Fox ...

(MAZA, 2008, p. 45). Em 2005, o valor somado dos fundos voluntários do México para a Corte e a CIDH foi de 225 mil dólares (HUMAN RIGHTS WATCH, 2006, p. 20).

7. Comissão Interamericana de Direitos Humanos. Informe $\mathrm{N}^{0} 43 / 96$, Caso 11.430, México. 15 de outubro de 1996. Disponível em: <http://www.cidh.oas. org/annualrep/ 96span/Mexico11430.htm>. Acesso em: 5 jul. 2009.

8. Em fevereiro de 2001, Jorge Castañeda já havia aceitado o pedido de extradição feito pelo juiz espanhol Baltasar Garzón, em setembro de 2000. No entanto, Cavallo recorreu da decisão, e foi apenas em 2003 que a Suprema Corte de Justiça mexicana autorizou a extradição.

9. Os casos do general Francisco Gallardo e dos camponeses ecologistas haviam mobilizado as ONGs mexicanas e internacionais nos anos anteriores, que haviam realizado inúmeras campanhas pela libertação de todos eles.

10. Por guerra suja se conhecem as medidas de repressão militar e política empreendidas pelo PRI desde finais dos anos 1960 até início dos anos 1980 que buscavam a dissolução dos movimentos de oposição política e armada contrários ao Estado mexicano.

11. Comisión Nacional de los Derechos Humanos (CNDH). Recomendación 26/2001. Disponível em: <http://www.cndh.org.mx/comsoc/compre/2001/146. htm>. Acesso em: 20 jun. 2009.

12. A FEMOSPP, por seu turno, encerrou suas atividades em novembro de 2006 com o término do governo Fox, e suas investigações foram transferidas para a Coordenação Geral de Investigação da Procuradoria Geral da República (PGR).

13. Digna Ochoa, advogada e ativista de direitos humanos do Centro Prodh, foi alvo de várias ameaças de morte na década de 1990, a ponto de em 1999 a Corte Interamericana de Direitos Humanos ordenar medidas preventivas para proteger sua vida e integridade física. Em 19 de outubro de 2001, foi encontrada morta, fato que logo levantou suspeitas sobre a possibilidade de homicídio e desatou a pressão de inúmeras ONGs mexicanas e internacionais sobre o governo para que ele investigasse o caso. Pressionado, o governo solicitou à CIDH que designasse um especialista independente para que avaliasse e revisasse as investigações realizadas, e apresentasse um informe final com suas conclusões. No entanto, nem a CIDH nem a Comissão de Direitos Humanos do Distrito Federal (CDHDF) se posicionaram sobre se o caso era de suicídio ou homicídio, e por fim as investigações concluíram que a ativista havia se suicidado em razão de um quadro depressivo. 
14. Anaya lembra, nesse sentido, que a Comissão Intersecretarial "tinha o objetivo de coordenar os esforços do governo para responder às acusações feitas por ONGs e ao número crescente de pedidos de informações por partes de órgãos intergovernamentais" (ANAYA, 2009, p. 47-48).

15. Da Comissão, participavam de maneira formal, com voz, mas sem direito de voto, organizações da sociedade civil que contribuíam com seus comentários para a definição de políticas e leis que o governo deveria implantar para assegurar o respeito aos direitos humanos no país.

16. Entrevista pessoal com Edgar Córtez, secretário executivo da Red Nacional de Organismos Civiles de Derechos Humanos "Todos los Derechos para Todas y Todos”, 10 de novembro de 2008, México, Distrito Federal; entrevista por telefone com Michele Maza, ex-ativista do Centro de Derechos Humanos Miguel Agustín Pro Juárez (Centro Prodh), 11 de dezembro de 2008, México, Distrito Federal; e entrevista pessoal com Alfonso García, do Centro de Derechos Humanos "Fray Francisco de Vitoria, O.P." A.C., 27 de outubro de 2008, México, Distrito Federal. O ponto foi também levantado por Miguel Concha Malo em conferência no Colegio de México, de 4 de dezembro de 2008, intitulada "Balances de la política de derechos humanos en México, 1988-2008”.

17. Entrevista pessoal com Alfonso García, do Centro de Derechos Humanos “Fray Francisco de Vitoria, O.P.” A.C., 27 de outubro de 2008, México, Distrito Federal.

18. De acordo com Alfonso García, da ONG Fray Franciso de Vitoria O.P., "era mais prioritário trabalhar aqui [no México] em todos esses espaços que eram criados [dentro do governo Fox], apoiando a criação do Diagnóstico, do Programa Nacional de Direitos Humanos, coisas assim" (entrevista pessoal, 27 de outubro de 2008, México, Distrito Federal).

19. A política antes adotada pelos governos Salinas e Zedillo entre 1989 e 2000 havia sido a de votar contra ou se abster no caso das resoluções apresentadas sobre a situação dos direitos humanos em Cuba na Comissão de Direitos Humanos da ONU. O governo Fox, no entanto, rompeu esta política, e votou a favor de resoluções que condenavam a situação dos direitos humanos na ilha entre 2002 e 2005.

20. Entrevista por telefone com Jorge G. Castañeda, ex-secretário de Relações Exteriores do México, 22 de novembro de 2008, México, Distrito Federal.

21. Mariclaire Acosta, Jorge Castañeda, Adolfo Aguilar Zinser e Santiago Creel, entre outros, chegaram ao governo depois de longa experiência de ativismo na 


\section{A Política Externa Mexicana de Direitos Humanos du-}

rante o Governo Fox ...

sociedade civil. Mariclaire Acosta foi subsecretária de Direitos Humanos e Democracia da Secretaria de Relações Exteriores, entre 2001 e 2003; Jorge Castañeda foi secretário de Relações Exteriores entre 2001 e 2003; Adolfo Aguilar Zinser foi conselheiro presidencial de Segurança Nacional (2000-2002) e embaixador do México ante a ONU até 2003; e Santiago Creel foi secretário de Gobernación até 2005. Como ativistasm esses personagens haviam aprendido a utilizar o âmbito internacional na luta pelos direitos humanos e pelo avanço da democracia no país para pressionar os governos do PRI. Essa experiência de ativismo foi importante depois quando eles ingressaram no governo Fox. O uso estratégico do ambiente internacional para obter fins domésticos era já algo bastante conhecido para eles, que se haviam oposto inúmeras vezes, no passado, ao governo mexicano quando ele invocava as normas de soberania e não intervenção para tentar se blindar de críticas externas. Assim, parte da agenda e das estratégias que haviam defendido na sociedade civil enquanto ativistas de direitos humanos foi levada por eles para o governo.

22. Castañeda nota que as conversas com Felipe González convenceram muito Fox da ideia de ancorar a transição democrática no exterior. A posição do governo Fox foi influenciada, portanto, de maneira importante pela experiência do caso espanhol.

\section{Referências Bibliográficas}

ANAYA, Alejandro. Transnational and domestic processes in the definition of human rights policies in Mexico. Human Rights Quarterly, v. 31, p. 35-58, 2009.

COVARRUBIAS, Ana. El problema de los derechos humanos y los cambios en la política exterior. Foro Internacional, v. 39, n. 4, p. 429-452, oct.-dic. 1999.

Los derechos humanos en la política exterior de México: ¿en defensa propia o de los valores liberales? In: COVARRUBIAS, A. (Coord.). Temas de política exterior. México, D.F.: El Colegio de México, Centro de Estudios Internacionales, 2008. p. 303-332. 
CRESPO, José Antonio. ¿Tiene futuro el PRI? Entre la supervivencia democrática y la desintegración total. México: Grijalbo, 1998.

. Fronteras democráticas en México: retos, peculiaridades y comparaciones. México, D.F.: Editorial Oceano, 1999.

GONZÁLEZ, Guadalupe González. Las bases internas de la política exterior: realidades y retos de la apertura económica y la democracia. In: HERRERALASSO M., L. (Coord.). México ante el mundo: tiempo de definiciones. México, D.F.: Fondo de Cultura Económica, 2006. p. 155-235,

HAFNER-BURTON, Emilie; MANSFIELD, Edward D.; PEVEHOUSE, Jon C. Democratization and human rights regimes. Trabalho apresentado na reunião da International Studies Association (ISA), 2008. Disponível em: <http://ssrn.com/abstract=1123771>. Acesso em: 5 jun. 2010.

HUMAN RIGHTS WATCH. Lost in transition: bold ambitions, limited results for human rights under Fox. New York: HRW, 2006.

HUNTINGTON, Samuel P. A terceira onda: a democratização no final do século XX. São Paulo: Ática, 1994.

INFORME de Ejecución del PNDH 2005. México, D.F.: Secretaría de Gobernación/Comisión de Política Gubernamental en Materia de Derechos Humanos, 2005.

LUJAMBIO, Alonso. El poder compartido: un ensayo sobre la democratización mexicana. México: Océano, 2000.

MAGALONI, Beatriz. The demise of Mexico's one-party dominant regime: elite choices and the masses in the establishment of democracy. In: MAINWARING, S.; HAGOPIAN, F. (Ed.). The third wave of democratization in Latin America: advances and setbacks. Cambridge: Cambridge University Press, 2005.

MANSFIELD, Edward D.; PEVEHOUSE, Jon C. Democratization and international organizations. International Organization, v. 60, n. 1, p. 137-167, Winter 2006.

. Democratization and the varieties of international organizations. Journal of Conflict Resolution, v. 52, n. 2, p. 269-294, 2008. 
A Política Externa Mexicana de Direitos Humanos durante o Governo Fox ...

MAZA CALVIÑO, Emma Consuelo. Los derechos humanos en México: ¿retórica o compromiso? Tese (Mestrado em Direitos Humanos e Democracia) Facultad Latinoamericana de Ciencias Sociales (FLACSO), México, 2008.

MISIÓN PERMANENTE DE MÉXICO EN LA ONU. Contribuciones y promesas voluntarias de México a la promoción y protección de los derechos humanos. Nova Iorque, 11 abr. 2006.

MORAVCSIK, Andrew. The origins of human rights regimes: democratic delegation in postwar Europe. International Organization, v. 54, n. 2, p. 217-252, 2000 .

NACIONES UNIDAS. Asamblea General. Informe nacional presentado de conformidad con el párrafo 15 A) anexo a la Resolución 5/1 del Consejo de Derechos Humanos: México. Ginebra: Consejo de Derechos Humanos, Grupo de Trabajo sobre el Examen Periódico Universal, A/HRC/WG.6/4/MEX/1, 10 nov. 2008.

ORTIZ, Reynaldo Yunuen Ortega. Movilización y democracia: España y México. México, D.F.: El Colegio de México, Centro de Estudios Internacionales, 2008.

SECRETARÍA DE RELACIONES EXTERIORES. La política exterior mexicana en la transición. México: FCE, SRE, 2005.

TREVIÑO RANGEL, Javier. Las ONG de derechos humanos y la redefinición de la soberanía del Estado mexicano. Foro Internacional, v. 44, n. 3 (177), jul.-sep. 2004.

WHITEHEAD, Laurence. Consecuencias de la democratización en la política exterior de México. In: COVARRUBIAS, A. (Coord.). Temas de política exterior. México, D.F.: El Colegio de México, Centro de Estudios Internacionales, 2008. p. 365-388. 


\section{Resumo}

\section{A Política Externa Mexicana de Direitos Humanos durante o Governo Fox (2000- 2006): As Estratégias de Lock-in e Sinalização}

O objetivo deste artigo é analisar as relações entre a democratização do México e a sua política externa de direitos humanos durante o governo Fox, explorando o impacto da transição democrática na adoção de uma plataforma inédita de política externa que transformou os direitos humanos em um tema central das relações exteriores do país. O argumento defendido é o de que as alterações observadas no comportamento internacional do Estado podem ser explicadas por cálculos endógenos ao próprio governo que com elas buscava ancorar a transição democrática no exterior e sinalizar a credibilidade e seriedade de suas credenciais democráticas.

Palavras-chave: México - Política Externa - Democratização - Direitos Humanos

\section{Abstract}

\section{Mexico's Human Rights Foreign Policy under the Fox Administration (2000- 2006): The Lock-in and Signaling Strategies}

The aim of this paper is to analyze the links between Mexico's democratization and its human rights foreign policy under the Fox administration, exploring the impact of the democratic transition on the adoption of a new foreign policy platform in which human rights became a central theme in Mexico's foreign affairs. We argue that the observed changes in the Mexican human rights foreign policy were initiated endogenously in the government, which expected to lock in Mexico's new democratic situation with international commitments and to assure international audiences of the credibility of its commitments to democratic reforms and human rights.

Keywords: Mexico - Foreign Policy - Democratization - Human Rights 